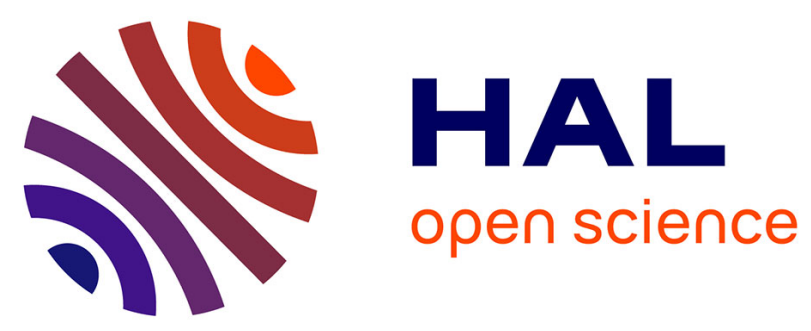

\title{
Trace Amine-Associated Receptor 1 Regulates Central Effects of Monoamine Oxidase Inhibitors: Involvement of Tyramine and Glutamate
}

Sophie Gautron

\section{> To cite this version:}

Sophie Gautron. Trace Amine-Associated Receptor 1 Regulates Central Effects of Monoamine Oxidase Inhibitors: Involvement of Tyramine and Glutamate. Biological Psychiatry, 2021, 90 (1), pp.2-3. 10.1016/j.biopsych.2021.04.021 . hal-03471288

\section{HAL Id: hal-03471288 \\ https://hal.sorbonne-universite.fr/hal-03471288}

Submitted on 8 Dec 2021

HAL is a multi-disciplinary open access archive for the deposit and dissemination of scientific research documents, whether they are published or not. The documents may come from teaching and research institutions in France or abroad, or from public or private research centers.
L'archive ouverte pluridisciplinaire HAL, est destinée au dépôt et à la diffusion de documents scientifiques de niveau recherche, publiés ou non, émanant des établissements d'enseignement et de recherche français ou étrangers, des laboratoires publics ou privés. 
Trace amine-associated receptor 1 regulates central effects of MAO inhibitors: involvement of tyramine and glutamate

\section{Sophie Gautron}

Article information

From the Institut of Biology Paris-Seine, INSERM, CNRS, Sorbonne Université, 75005 Paris, France

Address correspondence:

Sophie Gautron, Ph. D., Neuroscience Paris-Seine

E-mail: sophie.gautron@inserm.fr 
Trace amines constitute a group of endogenous molecules found in both invertebrates and vertebrates, bearing strong similarities with the monoamine neurotransmitters. The physiological significance of these molecules has long remained elusive, until the discovery in 2001 of a large subfamily of G-protein coupled receptors (GPCR) interacting with these compounds, the trace amine-associated receptors (TAAR) $(1,2)$. This major breakthrough spurred a regain of interest for trace amines and their role in the brain. TAAR1, the best-known member of this family, was found to interact with endogenous compounds including the trace amines p-tyramine, $\beta$-phenylethylamine, tryptamine and octopamine, the monoamines dopamine and serotonin, the thyroid hormone derivative 3-iodothyronamine (T1AM), as well as several psychoactive compounds like amphetamine (2). A profusion of studies using synthetic modulators including full and partial agonists and antagonists uncovered the importance of TAAR1 in central functions such as locomotor activity, attention and learning, emotional behavior, drug reward and wakefulness. This multifaceted role was comforted by genetic studies also suggesting its potential implication in schizophrenia, bipolar disorder and addiction (3).

In the current issue of Biological Psychiatry, Mantas et al. (4) investigate some of the processes at work in the effects of the monoamine oxidase (MAO) inhibitors in the brain and controlled by TAAR1. In a first set of experiments, the effects of MAO inhibitors, either tranylcypromine (TCP) or a combination of clorgiline and rasagiline, were compared in WT mice and TAAR1 knockout mice. The systematic administration of these MAO inhibitors led to an increase in antidepressant-like response and in locomotor activity in normal mice. Remarkably, these increases were found significantly stronger in TAAR1 knockout than in WT control mice, indicating that TAAR1 activity negatively regulates the behavioral effects of MAO inhibitors.

Next, to obtain a bird's-eye view of the various perturbations evoked in the brain by chronic administration of TCP, the content of monoamines, diamines and various metabolites was examined by MALDI mass spectrometry (MS) imaging on mouse brain sections. Exploiting the data generated by this powerful approach, the authors pinned-down tyramine as a main culprit in effects of TCP. Quantification of MALDI-MS imaging indicated that this trace amine was significantly enhanced after a chronic TCP treatment in the striatum of normal and TAAR1 knockout mice, and that this level after TCP was notably higher in TAAR1 knockout mice than in WT mice. Dopamine levels were also 
increased in this brain area after TCP, but remained unaffected by TAAR1 deletion, suggesting that in conditions of MAO inhibition TAAR1 exerts a negative control selectively on tyramine level. Interestingly, this enhancement of TCP-induced tyramine levels by TAAR1 deletion was correlated with a similar enhancement of locomotor activity in the TAAR1 mutants.

The neural correlates of the effects of TCP treatment on locomotor activity were next investigated by monitoring expression of the mRNA encoding the immediate-early gene Arc, in the striatum (4). In this region, approximately half of the medium spiny neurons (MSN) population, characterized by the expression of dopamine 1 (D1)-like receptors, project to the substantia nigra (the so-called "direct pathway) and has been shown to control positively locomotor activity. In these experiments, TCP treatment was found to increase arc mRNA expression in the striatum, concomitantly with the increase in tyramine level and locomotor activity. This neural activation, which appears to be due at least in part to increased activation of the D1 (dynorphin+) MSN population, was further increased in the TAAR1 mice mutant, consistently with the observed increase in locomotor activity. TAAR1 and dopaminergic neurons share a complex relationship, and several studies have shown that TAAR1 activation influences dopamine neuron activity. Whether these effects are excitatory or inhibitory is a matter of debate, and might vary depending on the region examined and the experimental paradigm $(5,6)$. The observation of Arc overexpression in TAAR1 mice mutants(4) is consistent with the view that trace amines via TAAR1 activation tone down DA neuron excitability, thereby decreasing DA release in the striatum.

These intriguing findings raised the question of how TAAR1 acts to modulate the nigrostriatal pathway activity. TAAR1 is expressed in monoaminergic circuits but also in brain areas containing glutamatergic neurons $(1,6)$. Multiple excitatory afferents from various brain regions converge on the substantia nigra (SN), exerting important modulatory effects on dopamine neuron activity (7), while SN dopaminergic neurons themselves are interspersed with glutamatergic neurons (8). Using the $\beta$ galactosidase reporter under the control of the TAAR1 promoter in TAAR1 knockout mice, Mantas et al (4) expand previous anatomical studies of TAAR1 expression by reporting yet unidentified expression sites in glutamatergic regions that send strong projections to the substantia nigra compacta (SNc) and VTA, such as BSTM, LHA, ZI and LPBD. These authors also provide original findings on how TAAR1 and tyramine influence glutamate release in the dopaminergic areas, in ventral midbrain. In a final series 
of experiments, they investigated using a biosensor-mediated electrochemistry technique the effects of TCP or tyramine on glutamate release in SNc in TAAR1 knockout mice and wild-type controls, using two paradigms. In anesthetized mice, local infusion of TCP in the SN area led to a decrease in glutamate release in this area, measured by FAST recording. This effect of TCP was mimicked by a local infusion of tyramine and appears to implicate TAAR1, since it was abolished in TAAR1 knockout mice and by local application of EPPTB, a TAAR1 antagonist. From these experiments, it could be concluded that TAAR1 was implicated in the negative modulation of glutamate release by TCP. Further reinforcing this demonstration, a similar effect was found using FAST recording in freely moving mice. These last experiments showed that glutamate release was increased by systemic TCP administration in TAAR1 KO mice but not in WT mice, correlated with an increase in locomotor activity. Although it is not clear from these experiments which glutamatergic neuronal populations may be implicated, and whether the glutamatergic terminals themselves within SNc express the TAAR1 protein, they reveal unequivocally the prevalent role of TAAR1 in the $\mathrm{SNc}$ in toning-down both glutamate release in this area and ambulation in anesthetized or awake animals, and favor a role of local tyramine. The contributions of the various glutamatergic circuits and populations potentially implicated in these effects of TAAR1 require further investigation. It is important to note that deregulation in glutamate transmission or in the activation of NMDA glutamate receptors was reported also for the cortex and striatum of TAAR1 mutant mice (9), suggesting an extended control of excitatory neurotransmission by TAAR1 in not only dopaminergic nuclei but also dopaminergic projection areas.

Apart from tyramine, MALDI-MSI imaging revealed the influence of TCP treatment on other amines such as histamine, taurine and the melatonin metabolite 6-hydroxymelatonin, whose levels seem also regulated by TAAR1 (4). Obviously, a host of information can be drawn from use of this powerful and innovative tool to examine the effects on other brain areas. Altogether, this original and comprehensive study enriches the knowledge on how TAAR1 acts to balance dopamine-related functions and glutamate signaling in the brain. Inasmuch MAO inhibitors may have not said their last word in the management of depression (10), the mechanisms disclosed also have a broader relevance for the understanding of the circuits implicated in the action of this class of antidepressants. 


\section{Acknowledgments and Disclosures}

The author reports no biomedical financial interests or potential conflicts of interest.

\section{References}

1. Borowsky B, Adham N, Jones KA, Raddatz R, Artymyshyn R, Ogozalek KL, et al. (2001): Trace amines: identification of a family of mammalian G protein-coupled receptors. Proc Natl Acad Sci U S A. 98:8966-8971.

2. Bunzow JR, Sonders MS, Arttamangkul S, Harrison LM, Zhang G, Quigley DI, et al. (2001): Amphetamine, 3,4-methylenedioxymethamphetamine, lysergic acid diethylamide, and metabolites of the catecholamine neurotransmitters are agonists of a rat trace amine receptor. Mol Pharmacol. 60:1181-1188.

3. Dodd S, A FC, Puri BK, Maes M, Bortolasci CC, Morris G, et al. (2021): Trace Amine-Associated Receptor 1 (TAAR1): A new drug target for psychiatry? Neurosci Biobehav Rev. 120:537-541.

4. Mantas I, Vallianatou T, Yang Y, Shariatgorji M, Kalomoiri M, Fridjonsdottir E, et al. (2020): TAAR1-Dependent and -Independent Actions of Tyramine in Interaction With Glutamate Underlie Central Effects of Monoamine Oxidase Inhibition. Biol Psychiatry.

5. Yang W, Munhall AC, Johnson SW (2020): Dopamine Evokes a Trace Amine Receptor-dependent Inward Current that is Regulated by AMP Kinase in Substantia Nigra Dopamine Neurons. Neuroscience. 427:77-91.

6. Lindemann L, Meyer CA, Jeanneau K, Bradaia A, Ozmen L, Bluethmann H, et al. (2008): Trace amine-associated receptor 1 modulates dopaminergic activity. J Pharmacol Exp Ther. 324:948-956.

7. Prisco S, Natoli S, Bernardi G, Mercuri NB (2002): Group I metabotropic glutamate receptors activate burst firing in rat midbrain dopaminergic neurons. Neuropharmacology. 42:289-296.

8. Morales M, Root DH (2014): Glutamate neurons within the midbrain dopamine regions. Neuroscience. 282:60-68.

9. Gainetdinov RR, Hoener MC, Berry MD (2018): Trace Amines and Their Receptors. Pharmacol Rev. 70:549-620. 
10. Suchting R, Tirumalajaru V, Gareeb R, Bockmann T, de Dios C, Aickareth J, et al. (2021): Revisiting monoamine oxidase inhibitors for the treatment of depressive disorders: A systematic review and network meta-analysis. J Affect Disord. 282:1153-1160. 